\title{
AMBIGUITIES IN ENGLISH: WHAT CAUSESTHEM AND HOW TO DISAMBIGUATE SENTENCES
}

\author{
Dr Aruna Kumar Behera, \\ Associate Professor \\ Dept of Language \& Literature, \\ Sri SathyaSai Institute of Higher Learning (Deemed to be University) \\ Bangalore-560 067 .
}

\begin{abstract}
Ambiguity simply refers to the potential of being open to more than one interpretation. In other words, whatever we say or write may have at least one meaning which leads to confusion or inexactness as far as the intent is concerned. Ambiguities can happen in many ways but lexical, syntactic and semantic ambiguities are some of the more common ones. In this paper we examine the various types of ambiguities; and why and how they creep in. We also suggest some means and ways to make our communication less ambiguous and clearer.
\end{abstract}

Keywords: Ambiguity, Speech, Writing, Lexical, Syntactic, Semantic

\section{Introduction}

The Cambridge Dictionary (2021) defines ambiguity as "something having more than one possible meaning and therefore possibly causing confusion." The simplest definition of ambiguity reads that an expression is ambiguous if the expression has more than one meaning (Gillion: 1990).It implies then that it is a type of meaning in which a phrase or a statement is not defined explicitly leaving the interpretation open to the reader or listener. Sentences or sometimes a set of sentences containing ambiguity may be written deliberately for effect. In some cases though, it may occur out of sheer ignorance. Notwithstanding the intent of the author, ambiguous sentences result in some or all of these effects, for example, humour, disgust, lack of civility, immorality, illegality etc. Of course, there is some elbow room for excuse in literature. One can always twist or tweak the intended or plausible meaning or interpretation and escape embarrassment or possibly punishment.

\section{Effects of Ambiguity}

Richards (1978) believes that an ambiguous word in a sentence makes it correspondingly ambiguous. In the sentence "Visiting relatives can be boring," for instance, the word 'visiting' creates ambiguity. This sentence thus can mean either of these two things: a) you feel bored when you visit them, or b) theact of visiting can be boring. One of the commonest aspects of ambiguity, therefore, is uncertainty, some other aspects being confusion, misinterpretation, 
vagueness, rudeness etc. However, Stageberg (1978) has a point when he says, "We are pattern-bound in language just as we are culture-bound in mores."

The sentence "Did you see her dress," which is vague, for it may mean whether somebody saw her wearing a dress or her clothes will put things in perspective. In addition to making the communication vague or confusing, ambiguity may, at times, make it humorous, disgusting, or even uncivil rendering the message fail."Kids make nutritious snacks," can make people roar with laughter (it may mean kids prepare snack or you eat kids as snack).It may also lead to moral or even legal action depending on the people involved, their cultural moorings, their countries or states. Similarly, the sentence, "Don't kill your wife with work! Let electricity do it" may land up the speaker behind bars for offering a suggestion to his friend to eliminate the latter's wife.

\section{Types of Ambiguity}

There are primarily three major types of ambiguities, viz. 1) lexical ambiguity, 2) semantic ambiguity, and 3) syntactic ambiguity.

\section{Lexical Ambiguity}

Lexical ambiguity occurs when a lexis or word has more than one meaning or interpretation. The word 'bank', for example, has several meanings: i) a financial institution, ii) an edge of a river, iii) to depend on etc. The ambiguity arises from the way in which a particular word is used as in the case: "He buried money in the bank" which may mean that "he put the money in the bank' or alternatively 'he dug up a hole in the sands on the bank of a river and hid the money' (the second meaning is less likely though).Lexical ambiguity can further be distinguished in to two types: homonymy and polysemy (Durda, et al: 2010).Though conventionally, polysemy and homonymy are described in the context of lexical relations and are assigned several meanings, Crystal (2008) sets everything to rest when he says that ambiguity refers to a situation where a word or construction "expresses more than one meaning."

Polysemy (which comes from the Greek words poly- and sêma meaning many signs) refers to one word having multiple meanings, e.g. 'foot' as in the foot of a person, the foot of a hill etc.; or 'present' which may mean now, gift, to produce somebody or something, or to be physically available etc.

Homonymy, on the other hand, refers to two or more words that have the same sound or spelling but have different meanings, e.g. 'bark'which means the skin of a tree, or the barking of a dog. Both cases involve an ambiguous word form, and the difference lies in how the information is organized in the speaker's mental lexicon.The term homonym refers

to homophones (words that are pronounced the same but have different meanings, such as 'desert' and 'dessert' or 'knead' and 'need') and homographs (words that are spelled the same but have different meanings as in 'fine' or 'lie').It is, of course, true that it is not easy to draw a clear boundary between 
International Journal of Trends in English Language and Literature (IJTELL) An International Peer-Reviewed English Journal; Volume-2, Issue-3; 2021 $\underline{\text { www.ijtell.com }}$ Impact Factor: 5.144(SJIF)

ISSN: 2582-8487

these two types of ambiguity but many ambiguous words clearly belong to one type or the other and the examples below account for the argument:

The sentence "The fisherman went to the bank" is ambiguous because it may mean either the fisherman went to the river bank or to the financial institution. Similarly, another sentence "Time flies" may be interpreted in two ways: a person is asking another to record the time the flies take, ortime moves fast. One more sentence, "There's a nut behind the wheel" may mean something like a fool driving a vehicle, or the existence of a nut (and bolt) in the wheel. And advertisements like "We fly over a million people" also might be construed as the airlines having a million plus customers, or they fly above.

Similarly, the sentence "He saw her dress" is another example of lexical ambiguity, for it means he saw a lady wearing her clothes or he found her clothes. An equally ambiguous sentence is "Farmer Bill dies in House" which means: a farmer by name Bill dies, and the bill relating to farmers falls through in the legislature. "Drunk gets nine months in violin case" is an interesting illustration for it means either the drunken person is sent to jail in a case involving the violin or the drunken man stays inside the violin case. One more sentence: "Teacher strikes idle kids" whichcan mean that the strikes by the teachers leave the kids idle, or the teacher beats the kids who are sitting idle. Stageberg's (1978) has a point when he says, "It is also worth noting that lexical ambiguity, then, derives from the meaning of words not their structures."

\section{Semantic Ambiguity}

Semantic means meaning. Wittgenstein (1953) states, "The meaning of a word is its use in the language." Semantic ambiguity occurs when a word, phrase or sentence, taken out of context, has more than one interpretation. Semantic ambiguity leads to an uncertainty because it has the plausibility of being interpreted in a way more than one. Semantic ambiguity can be looked upon from two angles: word ambiguity and sentence ambiguity. Semantics relate to several meanings such as conceptual, connotative, stylistic, affective, reflected, collocative and thematic. Let's look at some of the sentences below to understand semantic ambiguity: "Brave men run in my family" means two things: the family has brave people, or brave men in the family run. Another sentence, "Teachers who goof occasionally apologise" may mean that teachers frequently make mistakes or they apologise frequently. "We gave a table to a boy with painted legs" is an interesting sentence for it is confusing whether the leg of the table is painted or that of the boy.

But a hilarious example is: "The old man shot an elephant in pajamas." It may be interpreted as the elephant or the old man wearing pajamas. The phrase "New English Textbook" might refer to the textbook on the New English or the English Textbook which is new. Similarly, "Call me a taxi" is a sentence which means either the speaker is asking someone to hail them a taxi or to be called a taxi. Here is one more: "Milk drinkers are turning to powder." It could mean either the people who drink milk are becoming powder or those drinking milk are going in for milk 
International Journal of Trends in English Language and Literature (IJTELL) An International Peer-Reviewed English Journal; Volume-2, Issue-3; 2021

powder. The sentence "Lack of brains hinders research" is ambiguous for it conveys two meanings: research activity gets affected because there is no brain matter or it gets affected because there are no smart people. According to Empson (1930), "ambiguity, in ordinary speech, means something very pronounced, and as a rule witty or deceitful."

\section{Syntactic Ambiguity}

Syntactic ambiguity arises when a sentence can have two (or more) different meanings because of the structure of the sentence which is called its syntax. Akmajian et al (2004) feels that structural ambiguity takes place when no particular word is ambiguous rather the "ambiguity is due to structural relations in the sentence."It occurs mainly because of a modifying expression, for example a prepositional phrase as in the sentence "I saw someone on the hill with a telescope" which could mean that I saw a man through a telescope or saw a man who was holding a telescope. Similarly, the sentence "We painted the wall with cracks" is confusing for it may mean that we painted the wall that had cracks or we caused cracks to the wall. "The burglar threatened the student with the knife" is one more example of ambiguity because it could mean either of the two things: the burglar was wielding a knife or the student was.

Let's see some more sentences: "Ron kissed his wife, and so did Richard" may be misconstrued as Ron kissed his wife and Richard also kissed Ron's wife. One more example: "Mary got the bath ready for her daughter wearing a bluegown." It's not clear who was wearing blue gown: Mary or her daughter. Similarly, the sentence "There is a bird in a cage that can talk" could mean either of the two: the bird or the cage can talk. In the sentence "Fat people eat accumulates,' it means that fat people eat accumulates or the fat accumulates in people. An interesting example is: "The cotton clothing is usually made of grows in Mississippi." It could mean the cotton grows in Mississippi or the clothing is made of grows.

Structural ambiguity occurs when a phrase or sentence has more than one underlying structure, as can be seen in the phrases "beautiful girls hostels"/ "beautiful girls' hostels"/ (beautiful-girls or hostel?), "twenty five dollar bills"/ "twenty-five dollar bills" (25 pieces of dollars or one 25 dollar note?), "small business owner"/ "small-business owner" (small-business or the owner), and "man eating bird"/ "maneating dog" (man eats bird or bird eats man?).

Similar is the case with sentences: "Man eating piranha mistakenly sold as pet fish"/ "Man-eating piranha mistakenly sold as pet fish" (could mean man who eats piranha or piranha which eats man...), "A woman without her man is nothing"/ "A woman: without her, man is nothing" (may mean a woman is nothing without her man or man is nothing without a woman), "Thank you! Your contribution just helped a person get well"/ "Thank you! Your contribution just helped a person. Get well" (has two possible meanings: your contribution helped a person get well or bless you for your contribution, you should get well) or "Private property. No! 
Swimming allowed"/ "Private property. No swimming allowed" (it's not a private property, so swimming is allowed, or it's a private property and swimming is not allowed). These ambiguities are said to be structural because each such phrase can be represented in two structurally different ways. Indeed, the existence of such ambiguities provides strong evidence for a level of underlying syntactic structure.

\section{Ambiguities in Passages}

We examined, in the preceding paragraphs, the ambiguities pertaining to phrases and sentences. Let's see how it works in passages. We cite below two versions of a letter ${ }^{1}$ to show how ambiguity affects the intended meaning and leads to different or rather opposite interpretations.

Dear John:

I want a man who knows what love is all about. You are generous, kind, thoughtful. People who are not like you admit to being useless and inferior. You have ruined me for other men. I yearn for you. I have no feelings whatsoever when we're apart. I can be forever happy--will you let me be yours?

--Jane

Dear John:

I want a man who knows what love is. All about you are generous, kind, thoughtful people, who are not like you. Admit to being useless and inferior. You have ruined me. For other men, I yearn. For you, I have no feelings whatsoever. When we're apart, I can be forever happy. Will you let me be? Yours -Jane
The firstversionexhibits Jane's appreciation and love forJohn and she wishes to be with him for ever, while the second version (with some change with respect to punctuation alone) is exactly the opposite. She fumes at John and asks him to leave her alone.

\section{Why Ambiguities?}

From a laymen's perspective, our writing looks ambiguous either because we deliberately want to create an effect or because we are ignorant of the rules. Whatever may be the reason, ambiguity,according to some, actually makes language more efficient, by allowing for the reuse of short, efficient sounds that the audience can easily disambiguate with the help of context. It leads us tobelieve then that ambiguous words or phrases are helpful especially when we want to share something which may not be to the taste of the audience. So we avoid using direct and clear communication and use a euphemism instead.

One more case: the sentence "I convinced her children are noisy," can mean telling her that children generally are noisy instead of accusing her of her children being noisy to save her from embarrassment. Another example of ambiguity being used for effect is to create humour or make a serious thing light. The letter ${ }^{2}$ from Matthew to his mother-in-law (both the versions use the same words but vary in punctuations), for example,can save Matthew from his wife's wrath. In the first version, Matthew is not happy that his mother-in-law stayed with them whereas in the secondversion, he is really excited to have her stay with them again. 
Dear Mother-in-Law,

It was a shame you had to stay here. For such a short time, I thought I might have coped, but it was unbearable. Seeing you leave, the relief was immense. When I heard we might see you again soon, I wanted to end it all. By saying goodbye now, I hope I will not have to say it to you again for a long time. If you have the opportunity to spend Christmas elsewhere next year, please do.Not much love

\section{- Matthew}

Dear Mother-in-Law,

It was a shame you had to stay here for such a short time. I thought I might have coped, but it was unbearable seeing you leave. The relief was immense when I heard we might see you again soon. I wanted to end it all by saying goodbye now. I hope I will not have to say it to you again for a long time. If you have the opportunity to spend Christmas elsewhere next year, please do not.

Much love

- Matthew

The second reason why ambiguity is used is the language user's ignorance of rules, especially those pertaining to a) polysemy and homonyms, b) punctuations, and c) antecedents.

a) The words 'bank' (a financial institution, edge of a river, to depend), 'hand' (arm, support), 'watch' (see, time piece), 'lie' (cheat, to rest)etc., for example, mean more than one in each case as in the sentences: "The fisherman went to the bank", "The young man asked for her hand", "An ambassador lies abroad for his country" respectively. Similarly, people use homonymous words such as 'bat' (cricket bat, animal), 'spring' (tool, water body), 'mean' (lowly, average) etc. without realising the difference thus making possible misunderstanding as in the sentences: "I saw bats", "Have you seen a spring?", "It's a mean..." respectively.

b) Punctuations pose lots of ambiguities. The examples given below account for the argument:

The sentence "I saw a man, eating lobster" (the man was eating lobster) is opposed to the sentence "I saw a man-eating lobster" (the lobster was eating man). Similarly, "Now, my friends, listen to me" (means that somebody is asking people to listen) but "Now my friends listen to me" (means he is urging people to listen). One more example of ambiguity pertaining to punctuation is: "Kill him, not leave him" (kill him) as against "Kill him not, leave him" (don't kill him). The sentence, "Safety experts say, 'school bus passengers should be belted" means that experts advise passengers to wear belt while the sentence "Safety experts," say school bus passengers, "should be belted", means that the passengers advise the experts to wear belt. One more example: "We are going to learn to cut and paste kids" means that we are going to cut kids, and "We are going to learn to cut and paste, kids" means we are going learn cut...

c) There are ambiguities too that arise out of unclear antecedents. In the sentence "President George Washington and his vice president, John Adams, had a difficult relationship, which he wrote about in letters to friends," for example, 'he' could refer to Washington or Adams, leaving 
International Journal of Trends in English Language and Literature (IJTELL) An International Peer-Reviewed English Journal; Volume-2, Issue-3; 2021

people to guess. Similarly, in the sentence "When Elizabeth joined Gracie in the business, she did not know that she would be a failure", it is not clear whether the second 'she' refers to Elizabeth or Gracie. One more instance of ambiguity: "With her phone in one hand and her camera in the other, Joseph snapped photos with it as the show began." In this case, we are not sure whether the word 'it' refers to the phone or the camera. Let's see this sentence "Peter was found guilty of keeping a protected animal in the judge's court after being charged with removing a cobra from a doctor's clinic" which may mean if Peterwas guilty of keeping the snake in the judge's court, or guilty of keeping the snake after he caught it from a clinic).

\section{Eliminating ambiguity}

One of the purposes of any communication is clarity. We should be able to deliver the message clearly and without any ambiguity. However, as discussed in the preceding paragraphs, ambiguities creep in in our writing or speech either intentionally for effect or due to ignorance of rules. Our attempts, therefore, should be to make the sentences or expressions devoid of any ambiguity or at least less ambiguous which can be achieved by the following means:

One of the easiest ways to make the sentences clear is to keep them simple (and short) while following the syntax, that is, starting every statement with the subject, following closely with the verb, and ending with one or two objects, for example, $\mathrm{S}+\mathrm{V}+\mathrm{O}(+\mathrm{O})$, and each of these elements should contain the correct word
order.Sentences such as: "The black old Hindi-speaking Americangentle man has been working for a not-for-profit local organisation since he was a boy" or "English is one of the largest spoken international languages in the world" or "The sea route to India was discovered by Vasco da Gama."

Another way in which ambiguity can be avoided is by following the rules of grammar such as placing all adjectives close to the word they modify, or using words consistently throughout a document, or being careful about antecedents, or focusing on correct punctuation. Also, we can remove ambiguities by using active voice, being careful about dangling participles, and absolute modifiers. Given below are some sentences with their corrected or rewritten versions to show how ambiguities can be minimised and clarity achieved:

"Inspired by storylines that would come to him in dreams, Mike would stage one-man plays, his audience enjoying the show" ("Mike would stage one-man plays that were inspired by storylines from his dreams; his audience would enjoy the shows"). Another sentence "The workshop will be held at a time to be determined later in the month" can be rewritten as "The time of the workshop will be determined later in the month" or "You needn't worry about experiencing any further delays in getting this shipment" needs to be reframed as "This shipment will arrive by the end of the week." Similarly, the sentence "Although only given serious attention in recent decades, the author had a devoted fan base in the 
time of his own" can be improvised as "Although only given serious attention in recent decades, the author had a devoted fan base in the time of his own time". One more sentence "When I entered her office, the manager was reading a memo to her personal secretary" can be less ambiguous this way: "When I entered the manager's office, she was reading a memo to her personal secretary."

\section{Conclusion}

Ambiguity is something that can be interpreted in more ways than one. Ambiguities can be lexical, syntactic and semantic. An ambiguous word in a sentence makes it correspondingly ambiguous. Ambiguities occur owing to several reasons, one of them being deliberate and the other, user's ignorance of rules with regard to polysemy and homonyms, punctuations, and antecedents. However, our communication needs to be clear and devoid of ambiguities which we can achieve by writing simple syntactic sentences besides using active voice, being careful about dangling participles and modifiers. The bottom-line is: we write for audience; so the less ambiguous our communication is, the clearer it becomes.

Reference

8fe43e91-f74e-43ca-b2ba71a57cb6b04.pdf (tamu.edu)

BBC NEWS | UK | Magazine | Saying thank you in style

Akmajian, A., R. A. Demers, A.K. Farmers and R. M. Harnish (2004).Linguistics: An introduction to language and communication. (5th ed.) New Delhi: Prentice-Hall. Baker, L. (1989). English Syntax.Cambridge: The MIT Press.

Crystal, D. (2008). A dictionary of linguistics and phonetics. (6th ed.) Oxford: Blackwell.

Durda, K., Caron, R. J., Buchanan, L. (2010). INFOR vol 48, no. 1.1-11.

Empson, William. (1930). Seven Types of Ambiguity. Read Books Ltd.

Stageberg, N. C. 1978. Lingua Pranca, AnAnology of Linguistic Humour. Indiana University Linguistics Club, Bloomington, IN. 